\title{
Effect of beta adrenoceptor antagonists on baroreceptor reflex sensitivity in hypertension
}

\begin{abstract}
High-pressure baroreceptor reflex sensitivity (BRS) was estimated by measuring the reflex heart rate response to pharmacologic elevation of blood pressure (phenylephrine, 150 to $200 \mu \mathrm{g}$ intravenously) in 18 patients with essential hypertension on two occasions: after a 4-wk placebo period and after 9 wk of incremental doses of oral timolol $(20,40$, and 60 $m g$ daily). On placebo, measurements were performed both before and after propranolol $(0.2 \mathrm{mg} / \mathrm{kg}$ intravenously). The level of cardiac vagal inhibition, estimated by the heart rate change after atropine $(0.04 \mathrm{mg} / \mathrm{kg}$ intravenously), was similar on placebo and on timolol, thereby permitting comparisons of BRS. BRS on placebo (before and after propranolol) correlated with BRS on timolol $(r=0.87$ and $0.90, p<0.001)$, attesting to the reproducibility of $B R S$ measurements. BRS was unchanged by either short-term (propranolol) or long-term (timolol) beta adrenoceptor inhibition. Results were similar in responders $(n=10)$, whose mean arterial blood pressure on timolol fell by $10 \mathrm{~mm} \mathrm{Hg}$ or more, and in nonresponders. The findings do not provide evidence for a change in gain of the baroreceptor reflex arc under conditions of short-or long-term beta adrenoceptor inhibition.
\end{abstract}

\author{
Geza Simon, M.D., Wolfgang Kiowski, M.D., and Stevo Julius, M.D. \\ Ann Arbor, Mich. \\ Hypertension Section, Department of Internal Medicine, University of Michigan
}

\begin{abstract}
Despite the widespread use of beta adrenoceptor antagonists in the treatment of hypertension, the mechanism of their antihypertensive action remains controversial. ${ }^{12}$ It has been suggested that beta adrenoceptor antagonists act by reducing cardiac responses to pressor stimuli; the attenuation of cardiac responses gradually condition (reset) the highpressure baroreceptors to regulate blood pressure at a lower level in hypertensive pa-
\end{abstract}

Received for publication Jan. 10, 1977.

Accepted for publication May 7, 1977.

Reprint requests to: Geza Simon, M.D., Veterans Administration Hospital (111Cl), 54th St. and 48th Ave., Minneapolis, Minn. 55417 . tients. ${ }^{14}$ The possibility that beta adrenoceptor antagonists decrease pressor responses by increasing baroreceptor reflex sensitivity also was suggested. ${ }^{8}$ Baroreceptor reflex sensitivity has been tested in normal subjects after single intravenous injections of propranolol and in hypertensive subjects receiving long-term propranolol therapy. ${ }^{8,13}$ In both cases, some increase in sensitivity was noted, but it did not reach statistical significance in the hypertensive subjects. The number of subjects studied was small.

Our study was designed for two purposes: (1) to measure the effect of short- and long-term administration of beta adrenoceptor antagonists on the baroreceptor reflex sensitivity of patients 
Table I. Mean arterial blood pressure (MAP), heart rate $(H R)$, heart rate response to atropine $(\triangle H R$, atr), and baroreceptor slope $(B R S)$ in 18 patients with essential hypertension on placebo before and after propranolol and after 9 wk of timolol therapy (means $\pm S E M$ )

\begin{tabular}{l|c|c|c|c}
\hline \multicolumn{1}{c|}{ Treatment } & $\begin{array}{c}M A P \\
(m m \mathrm{Mg})\end{array}$ & $\begin{array}{c}H R \\
\text { (beats/min })\end{array}$ & $\begin{array}{c}\Delta H R(\text { atr }) \\
\text { (beats } / \text { min })\end{array}$ & $\begin{array}{c}\text { BRS } \\
(\mathrm{msec} / \mathrm{mm} \mathrm{Hg})\end{array}$ \\
\hline $\begin{array}{l}\text { Placebo } \\
\quad \text { Rest }\end{array}$ & $107 \pm 3.5$ & $59 \pm 2.0$ & - & $13.6 \pm 2.06$ \\
$\quad \begin{array}{l}\text { Propranolol } \\
\quad(0.2 \mathrm{mg} / \mathrm{kg} \text { intravenously) }\end{array}$ & $107 \pm 2.9$ & $54 \pm 1.6^{*}$ & $35 \pm 4.0 \dagger$ & $13.8 \pm 2.34$ \\
$\quad$ Timolol (60 mg/day) & $98 \pm 3.4 \ddagger$ & $48 \pm 1.4^{*}$ & $36 \pm 3.2 \dagger$ & $14.2 \pm 1.96$ \\
\hline
\end{tabular}

${ }^{*} \mathrm{p}<0.001$ by paired Student's $\mathrm{t}$ test for comparison with measurements obtained at rest on placebo.

$\mathrm{t}_{\mathrm{n}}=16$.

†p $<0.05$ by paired Student's $t$ test for comparison with measurements obtained at rest on placebo.

with essential hypertension and (2) to test the hypothesis that an increase in baroreceptor reflex sensitivity contributes to the antihypertensive action of beta adrenoceptor antagonists.

The study is part of a more extensive investigation of the antihypertensive properties of timolol maleate currently in progress at our institution. Timolol maleate is a pure beta inhibitor without membrane-stabilizing or sympathomimetic activity. In its pharmacologic action timolol resembles propranolol, but on a weight for weight basis it is 5 to 10 times as potent as propranolol. ${ }^{1,2}$

\section{Materials and methods}

Our subjects were 18 men, aged 42 (range, 23 to 56) yr, with uncomplicated mild or moderate essential hypertension. Secondary causes of hypertension were excluded by clinical examination, rapid-sequence intravenous pyelography, and laboratory studies (serum creatinine and electrolytes, urinalysis, and urinary epinephrine and norepinephrine).

All antihypertensive medications were discontinued and all subjects were given placebo, one tablet twice daily for $4 \mathrm{wk}$, followed by three consecutive 3 -wk periods of incremental doses of timolol, 20, 40, and $60 \mathrm{mg}$ daily, in 2 divided doses. The subjects were seen at the end of the placebo period and at the end of each 3-wk treatment period. Patient compliance was monitored by pill counts. No other cardiac or antihypertensive medications were given during the study. The subjects were studied on two occasions: after the 4-wk placebo period and at the end of the 9-wk treatment period when every subject had been taking $60 \mathrm{mg}$ of timolol for at least $3 \mathrm{wk}$.

Experiments were performed in the morning after a 24-hr hospital stay with the subjects fasted for $10 \mathrm{hr}$ and in the supine position. The method of Smyth and co-workers ${ }^{16}$ in which the reflex heart rate response to pharmacologic elevation of the blood pressure is measured, was used to estimate the high-pressure baroreceptor reflex sensitivity. Brachial artery pressure was recorded via an intra-arterial catheter connected to a Statham P23Db transducer. Intra-arterial pressure was raised 20 to $40 \mathrm{~mm} \mathrm{Hg}$ by intravenous bolus injections of phenylephrine ( 150 to $200 \mu \mathrm{g})$ administered through a catheter inserted in an antecubital vein. Injections were performed in duplicate or triplicate. Arterial blood pressure and lead II of the electrocardiogram were recorded simultaneously on a Hewlett-Packard $4578 \mathrm{~A}$ polygraph at 25 $\mathrm{mm} / \mathrm{sec}$ paper speed during and for 40 to $60 \mathrm{sec}$ following the completion of the injections. During the first study, while the subjects were on placebo, the injections and the measurements were repeated $10 \mathrm{~min}$ after the administration of propranolol $(0.2 \mathrm{mg} / \mathrm{kg}$ intravenously).

The sensitivity of the high-pressure baroreceptors of each subject was estimated by plotting the R-R interval from the electrocardiograph for each heartbeat against the systolic blood pressure of the preceding beat for 20 to $30 \mathrm{sec}$, from the start of the rise of pressure to just before the peak pressure, by means of the techniques of Smyth and co-workers. ${ }^{16}$ All beats during inspiration and expiration were included into the calculations, a modification in- 


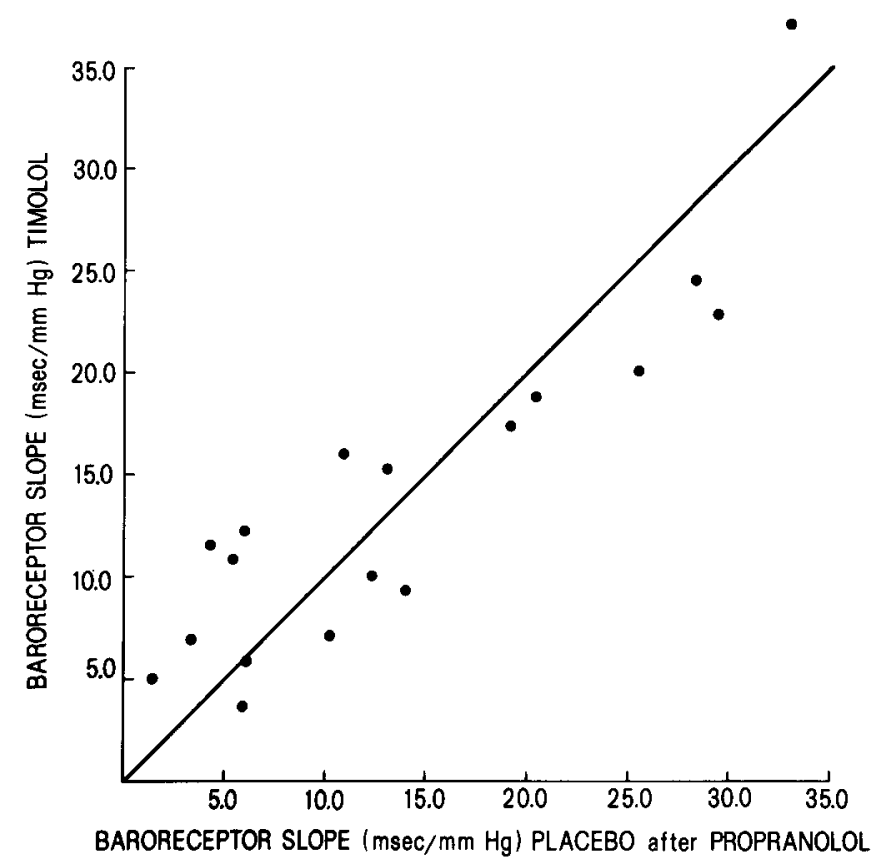

Fig. 1. Correlation of baroreceptor slope after short-term beta adrenoceptor inhibition with propranolol with baroreceptor slope after long-term timolol treatment in 18 patients with essential hypertension.

troduced by Bristow and colleagues. ${ }^{5}$ The plot of R-R intervals: systolic blood pressures was analyzed for linear correlation. The reflex sensitivity was expressed as the slope of the regression line. The slope was used for comparisons only if the $r$ value (correlation coefficient) in an individual was greater than 0.60 and the $p$ value was less than 0.05 . Since duplicate or triplicate determinations in the same subject were averaged, a sufficient number of readings was available and none of the study participants had to be excluded.

Cardiac vagal inhibition was estimated by recording the heart rate change following the intravenous administration of atropine (0.04 $\mathrm{mg} / \mathrm{kg}) .{ }^{10}$ On placebo, the administration of atropine followed short-term beta inhibition with intravenous propranolol. In patients on oral timolol ( $60 \mathrm{mg}$ daily) atropine was administered following the completion of baroreceptor sensitivity measurements. Cardiac vagal inhibition is expressed as the change in heart rate following atropine ( $\Delta \mathrm{HR}$ atr).

Student's $t$ test, the $t$ test for paired observations, and correlation coefficients were calculated by means of the Midas (Constat)
Computer Program of the Statistical Research Laboratory at the University of Michigan.

\section{Results}

The average heart rates and mean arterial blood pressures and the average slopes of the regression lines, estimating baroreceptor reflex sensitivity, of 18 subjects on placebo and on timolol are summarized in Table I.

Average mean arterial blood pressure $(107 \pm 3.5$ [mean \pm SEM] $)$ on placebo at rest was unaltered following short-term beta inhibition with propranolol $(107 \pm 2.9)$ but decreased after 9 wk of timolol therapy to $98 \pm 3.4(\mathrm{p}<0.05)$. The average heart rate, which was $59 \pm 2.0$ beats $/ \mathrm{min}$ at rest and $54 \pm 1.6$ short-term after beta inhibition with propranolol $(\mathrm{p}<0.001)$, was reduced further by long-term timolol administration to $48 \pm 1.4(\mathrm{p}<0.001)$. Cardiac vagal inhibition, estimated by the heart rate change following the administration of atropine, was similar on placebo and on timolol. The average slopes of baroreceptor sensitivity, $13.6 \pm 2.06$ $\mathrm{msec} / \mathrm{min}$, on placebo at rest was unaltered by either short-term (propranolol) or long-term 
Table II. Mean arterial blood pressure (MAP), heart rate (HR), and baroreceptor slope (BRS) of 10 responders $*$ and 8 nonresponders on placebo and timolol (means $\pm S E M$ )

\begin{tabular}{l|c|c|c|c|c}
\hline \multirow{2}{*}{\multicolumn{1}{c|}{ Parameter }} & \multicolumn{3}{|c|}{ Placebo } & \multicolumn{2}{c}{ Timolol } \\
\cline { 2 - 6 } & \multicolumn{2}{|c|}{ Responders } & Nonresponders & Responders & Nonresponders \\
\hline MAP (mm Hg) & $111 \pm 3.8$ & $102 \pm 6.2$ & $92 \pm 1.7 \dagger$ & $106 \pm 6.6$ \\
HR (beats $/ \mathrm{min})$ & $63 \pm 2.5 \dagger$ & $55 \pm 2.4$ & $50 \pm 1.8$ & $47 \pm 2.0$ \\
BRS (msec/mm Hg) & $13.3 \pm 2.62$ & $13.9 \pm 3.07$ & $15.6 \pm 3.16$ & $12.4 \pm 2.00$ \\
\hline
\end{tabular}

*Defined as $\geq 10 \mathrm{~mm} \mathrm{Hg}$ fall in MAP on $60 \mathrm{mg}$ of timolol.

$\dagger p<0.05$ for comparison of measurements in responders and nonresponders.

(timolol) beta inhibition. Baroreceptor sensitivity measurements in subjects on placebo before and after intravenous propranolol correlated with baroreceptor measurements on timolol $(\mathrm{r}=0.87$ and $0.90, \mathrm{p}<0.001)$, attesting to the reproducibility of these measurements (Fig. $1)$.

The same data were analyzed in terms of blood pressure response to long-term timolol administration (Table II). In 10 patients, defined as responders, mean arterial blood pressure was reduced by $10 \mathrm{~mm} \mathrm{Hg}$ or more. In the remaining 8 nonresponders, mean arterial blood pressure was unchanged or increased. On placebo, the average resting heart rate of responders $(63 \pm 2.5)$ was higher than that of nonresponders $(55 \pm 2.4, p<0.05)$. The differences in heart rate were no longer significant after long-term timolol administration. Average pretreatment mean arterial blood pressure and baroreceptor sensitivity were similar in the two groups. Neither responders nor nonresponders experienced changed baroreceptor sensitivity after long-term timolol therapy.

In these 18 patients with mild or moderate essential hypertension on placebo, baroreceptor sensitivity was inversely related to mean arterial blood pressure $(\mathrm{r}=0.51, \mathrm{p}<0.05)$ and to age $(\mathbf{r}=0.58, \mathrm{p}<0.05)$. There was no relationship between initial heart rate and baroreceptor sensitivity $(\mathrm{r}=0.01)$.

\section{Discussion}

The heart rate response following the intravenous injection of phenylephrine is reflex in origin, mediated via high-pressure baroreceptors, the contribution of low-pressure baroreceptors being small. ${ }^{11}, 15$ The reduction in heart rate can be measured precisely, unlike arterial dilatation, venous dilatation, and reduction in myocardial contractility, the other reflex effects of baroreceptor stimulation. These considerations led Smyth and associates ${ }^{6}$ and Bristow and co-workers ${ }^{5}$ to develop their methods, used in our study, to estimate baroreceptor reflex sensitivity. The conclusions drawn with the use of their methods should be limited to the baroreceptor-mediated reflex control of heart rate.

The early increase in R-R interval (bradycardia) following a transient rise in blood pressure is predominantly parasympathetic. Sympathetic effects become more important after about 30 sec. ${ }^{18}$ During the initial $30 \mathrm{sec}$, atropine (1.8 mg intravenously) abolishes the heart rate response to the blood pressure elevation. The lack of sympathetic involvement in the early heart response is demonstrated in our study; acute beta adrenoceptor inhibition with intravenous propranolol had no effect on baroreceptor reflex sensitivity. Our data are at variance with those of Pickering and co-workers ${ }^{13}$ who found an increase in baroreceptor reflex sensitivity after intravenous propranolol in 4 of 5 normotensive subjects. The discrepancy between their findings and ours may be due to the larger number of subjects studied by us or to differences in the response of hypertensive and normotensive subjects. Eckberg and associates ${ }^{6}$ measured the prolongation of the $\mathrm{R}-\mathrm{R}$ intervals during electrical stimulation of the carotid sinus nerve in patients who required baropacing for angina and found no change in reflex bradycardia following intravenous propranolol.

Since the baroreceptor-mediated reflex bradycardia as tested by the method of Smyth 
and associates ${ }^{16}$ is predominantly parasympathetic, the level of cardiac vagal inhibition at the time of testing may influence the degree of reflex bradycardia. ${ }^{16}$ Accordingly, since vagal activity cannot be increased further, a high initial vagal tone would be associated with an attenuated reflex bradycardia. In our study, vagal inhibition, as estimated by the heart rate response to atropine, was similar on placebo and on timolol.

The magnitude of reflex bradycardia following a transient rise in blood pressure is also dependent on the age of the subject, the level of physical exercise, the presence or absence of cardiovascular disease, the initial heart rate, and the level of blood pressure. ${ }^{3,5}, 7,9,17$ For the purposes of our study which involved paired comparisons in the same individuals, the contributions of initial heart rate and blood pressure are relevant. Finally, the question of the reproducibility of the baroreceptor responses must be considered.

In unanesthetized normotensive rabbits, Alexander and De Cuir ${ }^{3}$ noted a positive correlation between initial heart rate and the magnitude of reflex bradycardia. Initial heart rate had no effect on the reflex bradycardia of hypertensive rabbits. Smyth and colleagues ${ }^{16}$ found an opposite relationship between the initial heart rate and the reflex bradycardia in sleeping normal subjects; the steepest responses were recorded at the lowest resting heart rates. In our study, short-term beta adrenoceptor inhibition with propranolol reduced the heart rate. There was an additional decrease in heart rate following long-term beta adrenoceptor inhibition with timolol. The degree of reflex slowing of heart rate in our subjects, however, was independent of the heart rate prior to the injection of phenylephrine.

In human established and borderline essential hypertension the baroreceptor reflex sensitivity is decreased, although the basis for this is unclear. ${ }^{7,}{ }^{17}$ An inverse relationship between the severity of the hypertension and the reduction of baroreceptor reflex sensitivity was also noted by us as well as by others. ${ }^{7}{ }^{17}$ Therefore, the initial blood pressure level or the level of blood pressure attained on treatment with timolol may influence the baroreceptor reflex sensitivity.
However, the baroreceptor reflex sensitivity of our nonresponders whose blood pressure did not change and of our responders whose blood pressure fell significantly was similar on both placebo and timolol. Differences in the absorption of the drug between the two groups is an unlikely explanation, because a similar degree of beta adrenoceptor inhibition judged by responses to isoproterenol and exercise was achieved in the two groups.* The lowering of blood pressure over a period of 2 mo in responders was not associated with an increase in baroreceptor reflex sensitivity. We found the method of Smyth and associates ${ }^{16}$ to be highly reproducible, as attested by the high degree of correlation obtained between measurements taken in the same subjects on 2 different days 9 wk apart.

Animal experiments suggest that the increase in baroreceptor reflex sensitivity involves the central nervous system. ${ }^{4}$ The findings of our study do not provide evidence for a change in gain of the high-pressure baroreceptor reflex arc under conditions of short- or long-term beta adrenoceptor inhibition. Central sensitization of the baroreflex arc, such as that described for clonidine in animal experiments, does not seem to occur with the use of beta adrenoceptor antagonists, such as timolol, in the treatment of hypertensive patients. ${ }^{12}$ Unaltered cardiac vagal inhibition during therapy with timolol is additional evidence against a clinically significant central nervous system action of beta adrenoceptor antagonists. The antihypertensive action of beta adrenoceptor antagonists must be due to mechanisms other than the increased sensitivity of the high-pressure baroreceptor reflex.

*Unpublished observations.

\section{References}

1. Achong, M. R., Piafsky, R. M., and Ogilvie, R. I.: Duration of cardiac effects of timolol and propranolol, Clin. Pharmacol. Ther. 18:278-286, 1975.

2. Achong, M. R., Piafsky, R. M., and Ogilvie, R. I.: Duration of cardiac effects of timolol and propranolol, Clin. Pharmacol. Ther. 19:148-152, 1975.

3. Alexander, N., and De Cuir, M.: Loss of bar- 
oreflex bradycardia in renal hypertensive rabbits, Circ. Res. 19: 18-25, 1966.

4. Bard, P.: Anatomical organization of the central nervous system in relation to control of the heart and blood vessels, Physiol. Rev. 40(Suppl. 4):3-26, 1960.

5. Bristow, J. D., Brown, E. B., Cunningham, D. J. C., Howson, M. G., Petersen, E. S., Pickering, T. G., and Sleight, P.: Effect of bicycling on the baroreflex regulation of pulse interval, Circ. Res. 28:582-592, 1971.

6. Eckberg, D. L., Fletcher, G. F., and Braunwald, E.: Mechanism of prolongation of the R-R interval with electrical stimulation of the carotid sinus nerves in man, Circ. Res. 30:131-138, 1972.

7. Gribbin, B., Pickering, T. G., Sleight, P., and Peto, R.: Effect of age and high blood pressure on baroreflex sensitivity in man, Circ. Res. 29:424-431, 1971.

8. Hansson, L., Zweifler, A. J., Julius, S., and Hunyor, S. N.: Hemodynamic effects of acute and prolonged $\beta$-adrenergic blockade in essential hypertension, Acta Med. Scand. 196:27-34, 1974.

9. Higgins, C. B., Vatner, S. F., Eckberg, D. L., and Braunwald, E.: Alterations in the baroreceptor reflex in conscious dogs with heart failure, J. Clin. Invest. 51:715-724, 1972.

10. Jose, A. D., and Taylor, R. R.: Autonomic blockade by propranolol and atropine to study intrinsic myocardial function in man, J. Clin. Invest. 48:2019-2031, 1969.
11. Korner, P. I., West, M. J., Shaw, J., and Uther, J. B.: Steady state properties of the baroreceptor-heart rate reflex in essential hypertension in man, Clin. Exp. Pharmacol. Physiol. 1:6576, 1974.

12. Lewis, P.: The essential action of propranolol in hypertension, Am. J. Med. 60:837-852, 1976.

13. Pickering, T. G., Gribbin, B., Petersen, E. S., Cunningham, D. J. C., and Sleight, P.: Effects of autonomic blockade on the baroreflex in man at rest and during exercise, Circ. Res. 30:177. $185,1972$.

14. Prichard, B. N. C., and Gilliam, P. M. S.: Treatment of hypertension with propranolol, $\mathrm{Br}$. Med. J. 1:7-16, 1969

15. Robinson, B. F., Epstein, S. E., Beiser, G. D., and Braunwald, E.: Control of heart rate by the autonomic nervous system: Studies in man on the interrelation between baroreceptor mechanisms and exercise, Circ. Res. 19:400-411, 1966.

16. Smyth, H. S., Sleight, P., and Pickering, G. $\mathrm{W}$.: Reflex regulation of arterial pressure during sleep in man: Quantitative method of assessing baroreflex sensitivity, Circ. Res. 24:109-121, 1969.

17. Takeshita, A., Tanaka, S., Kuroiwa, A., and Nakamura, M.: Reduced baroreceptor sensitivity in borderline hypertension, Circulation 51:738-742, 1975.

18. Wang, S. C., and Borison, H. L.: An analysis of the carotid sinus cardiovascular reflex mechanism, Am. J. Physiol. 150:712-721, 1947. 